\title{
CPAP Decreases Lung Hyperinflation in Patients With Stable COPD
}

\author{
Agnaldo J Lopes MD PhD, Flávio POS Nery PT MSc, Felipe C Sousa PT, \\ Fernando S Guimarães PT PhD, Cristina M Dias PT PhD, Juliana F Oliveira PT PhD, \\ and Sara LS Menezes PT PhD
}

\begin{abstract}
BACKGROUND: Dynamic hyperinflation, caused by expiratory flow limitation, markedly increases resting end-expiratory lung volume (functional residual capacity) in many COPD patients. OBJECTIVE: To determine the impact and duration of impact of CPAP on hyperinflation and airway resistance in patients with stable COPD. METHODS: In a case series, 21 patients underwent $\mathrm{CPAP}$ at $8 \mathrm{~cm} \mathrm{H}_{2} \mathrm{O}$ for $15 \mathrm{~min}$, then whole-body plethysmography immediately after, and at 15 and 30 min after CPAP. RESULTS: The cohort's mean \pm SD age was $70 \pm 9 \mathrm{y}$, and the mean $F_{1} V_{1}$ was $41 \pm 8 \%$ of predicted. Residual volume, functional residual capacity, total lung capacity, the ratio of residual volume to total lung capacity, and airway resistance decreased after CPAP and did not significantly change at $15 \mathrm{~min}(P<.001)$, but returned to baseline at $30 \mathrm{~min}$. CONCLUSIONS: In patients with severe to very severe stable COPD, CPAP reduces lung volumes and airway resistance for $15 \mathrm{~min}$, but the lung volumes return to baseline by $30 \mathrm{~min}$. Key words: chronic obstructive pulmonary disease; COPD; continuous positive airway pressure; CPAP; pulmonary hyperinflation. [Respir Care 2011;56(8):1164-1169. (C) 2011 Daedalus Enterprises]
\end{abstract}

\section{Introduction}

The progression of COPD is associated with increased breathlessness, exercise intolerance, and impaired quality of life. Pulmonary rehabilitation is an efficient way to minimize the symptoms caused by COPD. CPAP has been used as an adjunct to pulmonary rehabilitation to reduce the work of the respiratory muscles and improve effort tolerance. ${ }^{1,2}$

\footnotetext{
Dr Lopes, Mr Sousa, and Drs Guimarães, Dias, Oliveira, and Menezes are affiliated with the Rehabilitation Science Graduate Program, Augusto Motta University, Rio de Janeiro, Brazil. Dr Lopes and Mr Nery are affiliated with the Laboratory of Respiratory Physiology, University of the State of Rio de Janeiro, Rio de Janeiro, Brazil. Drs Guimarães and Menezes are also affiliated with the School of Physiotherapy, Federal University of Rio de Janeiro, Rio de Janeiro, Brazil.
}

The authors have disclosed no conflicts of interest.

Correspondence: Agnaldo J Lopes MD PhD, Rehabilitation Science Graduate Program, Augusto Motta University, Rio de Janeiro, Brazil, Rua Araguaia 1266 bloco 1/405, Freguesia, Jacarepaguá, Rio de Janeiro, Brazil 22745-271. E-mail: phel.lop@uol.com.br.

DOI: $10.4187 /$ respcare.01092
As a result of dynamic hyperinflation caused by expiratory flow limitation, resting end-expiratory lung volume (functional residual capacity [FRC]) is markedly increased in many COPD patients. The increase in a subject's operating volumes at a given ventilatory rate expands the passive pressure load that needs to be overcome by the inspiratory muscles, and therefore, the work of breathing. ${ }^{3,4}$ Moreover, the time available for expiration may be insufficient to allow the system to return to end-expiratory lung volume. The residual inward elastic recoil creates a positive alveolar pressure at the end of expiration, known as auto-PEEP. 5

During mechanical ventilation, auto-PEEP is a common feature observed in COPD patients; however, it is also common in stable COPD patients, even in the absence of respiratory failure. ${ }^{6}$ The presence of auto-PEEP requires inspiratory muscles to generate sufficient force to overcome the opposite recoil pressure before inspiratory flow can begin. In this regard, auto-PEEP acts as an inspiratory threshold load and represents additional impedance contributing to both elastic work of inspiration and the sensation of dyspnea. COPD patients' respiratory muscles must, hence, generate more negative pleural pressure swings in order to initiate a breath during spontaneous and/or assisted ventilation. According to the "waterfall" 
theory, if auto-PEEP is the result of expiratory flow limitation, then extrinsic, applied PEEP at the airway opening should decrease the pressure gradient between the mouth and alveoli at end-expiration (the inspiratory load). ${ }^{7}$

The effects of CPAP on lower-airway function are poorly understood. In patients with stable COPD, the benefits of CPAP may be explained by a reduction in lung hyperinflation. ${ }^{6,8}$ Indeed, several investigators have found that applied PEEP can counterbalance auto-PEEP without causing further hyperinflation. ${ }^{9,10}$ CPAP and applied PEEP decrease the inspiratory load at any given volume, therefore reducing the increased work-load and improving lung mechanics until a critical PEEP value is reached. Some researchers suggested that a PEEP of $5-10 \mathrm{~cm} \mathrm{H}_{2} \mathrm{O}$ could partially decrease airway resistance $\left(\mathrm{R}_{\mathrm{aw}}\right)$, especially at the end of expiration, resulting in a faster and more uniform lung emptying. ${ }^{11,12}$ Applied PEEP above $10 \mathrm{~cm} \mathrm{H}_{2} \mathrm{O}$ increases hyperinflation and worsens respiratory mechanics, muscle activity, and hemodynamics. ${ }^{13,14}$

Given the few and contradictory results of studies on the influence of CPAP in patients with stable severe airway obstruction, we investigated the impact and duration of impact of CPAP on hyperinflation and $\mathrm{R}_{\mathrm{aw}}$ in patients with stable COPD.

\section{Methods}

Per the World Medical Association Declaration of Helsinki, this study was approved by the ethics committee of Augusto Motta University, and written informed consent was obtained from all participants. The study was performed in the Respiratory Physiology Laboratory at the University of the State of Rio de Janeiro, Rio de Janeiro, Brazil.

\section{Patients}

From January 2009 to February 2010, we prospectively studied COPD patients referred to our respiratory physiology laboratory. We recruited 25 patients whose spirometry indicated severe or very severe COPD. ${ }^{15}$ All the subjects had been or were heavy cigarette smokers. All the patients were stable (no COPD exacerbation in the previous 2 months), and had not taken any bronchodilators for $\geq 24 \mathrm{~h}$ before the protocol measurements.

\section{Experimental Procedures}

Figure 1 describes the sequence of measurements conducted with each patient. Spirometry (Collins Plus Pulmonary Function Testing System, Warren E Collins, Braintree, Massachusetts) was performed between 8:00 and 10:00 AM, according to the American Thoracic Society

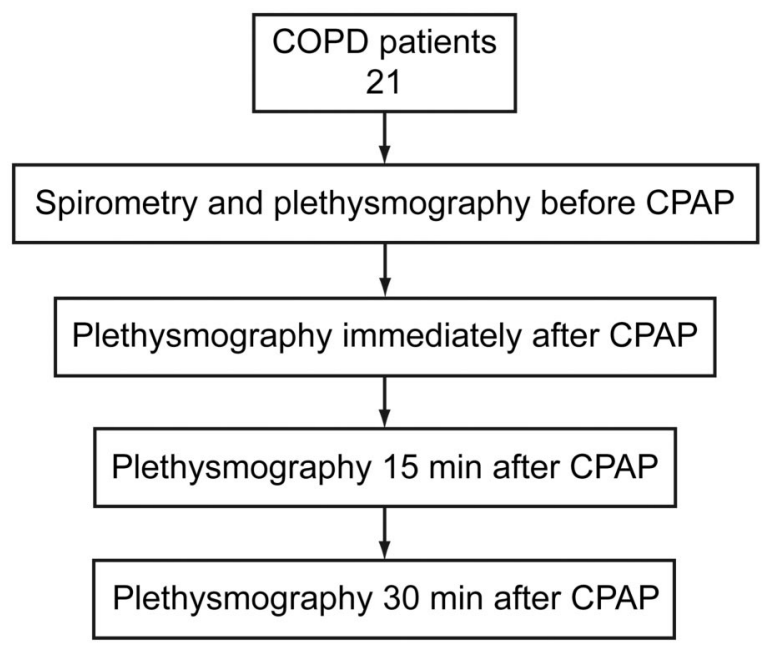

Fig. 1. Sequence of measurements.

standards. ${ }^{16}$ The results are expressed in absolute and percent-of-predicted values. ${ }^{17}$

After spirometry the subject underwent CPAP (Remstar Pro with C-Flex, Respironics, Murrysville, Pennsylvania) at $8 \mathrm{~cm} \mathrm{H}_{2} \mathrm{O}$, for $15 \mathrm{~min}$, in the sitting position, via face mask (Image III, Respironics, Murrysville, Pennsylvania), on room air. Before CPAP, immediately after CPAP, and 15 min and 30 min after CPAP we measured heart rate, $\mathrm{S}_{\mathrm{pO}_{2}}$ (Pulsox-3i, Minolta, Osaka, Japan), respiratory rate, and blood pressure.

Before CPAP, immediately after CPAP, and 15 min and 30 min after CPAP we measured lung volumes with a constant-volume, variable-pressure plethysmograph (Warren E Collins, Braintree, Massachusetts). Measurements were taken with the subject panting shallowly at a 1-2 breaths per second and supporting the cheeks and floor of the mouth with their hands to reduce compliance and minimize the volume changes of the mouth and pharynx. The reported thoracic gas volume was averaged from 3 to 5 acceptable panting maneuvers. We recorded inspiratory capacity, total lung capacity (TLC), FRC, residual volume (RV), RV/TLC, and $\mathrm{R}_{\mathrm{aw}}$. The results are expressed in absolute (static lung volumes and $\mathrm{R}_{\mathrm{aw}}$ ), and percent-ofpredicted values (static lung volumes). ${ }^{18}$

\section{Data Analysis}

We analyzed the data with statistics software (SAS 6.11, SAS Institute, Cary, North Carolina). We examined the effect of CPAP with repeated-measures 2-way analysis of variance. $P<.05$ was considered statistically significant. We conducted secondary analysis with the Bonferroni multiple-correction test, in which $P<.005$ was considered statistically significant. 


\section{CPAP Decreases Lung Hyperinflation in Patients With Stable COPD}

Table 1. Baseline Anthropometry and Respiratory Function Data $(n=21)$

\begin{tabular}{lc}
\hline \hline Male/female, no. & $12 / 9$ \\
Weight (kg) & $68.6 \pm 16.3$ \\
Height (m) & $1.6 \pm 0.7$ \\
Age (y) & $70 \pm 9$ \\
FVC (L) & $2.2 \pm 0.7$ \\
FVC (\% predicted) & $74 \pm 14$ \\
FEV $_{1}$ (L) & $0.96 \pm 0.40$ \\
$\mathrm{FEV}_{1}(\%$ predicted) & $41 \pm 8$ \\
FEV $_{1} /$ FVC $(\%$ predicted $)$ & $43 \pm 78$
\end{tabular}

All values except male/female are mean $\pm \mathrm{SD}$.

$\mathrm{FVC}=$ forced vital capacity

\section{Results}

Four patients were unable to perform body plethysmography and were excluded. The remaining 21 patients completed the study measurements (Table 1). Table 2 shows the effects of CPAP on the respiratory and hemodynamic variables. There was a statistically significant difference in respiratory rate and $\mathrm{S}_{\mathrm{pO}_{2}}(P<.001)$.

Table 3 shows the plethysmography results. All the differences were statistically significant $(P<.001$ via analysis of variance). Immediately after CPAP, inspiratory capacity was significantly increased (Fig. 2), and TLC (Fig. 3), RV (Fig. 4), and $\mathrm{R}_{\mathrm{aw}}$ (Fig. 5) were significantly decreased.

\section{Discussion}

CPAP decreased lung hyperinflation and $\mathrm{R}_{\mathrm{aw}}$ in patients with stable but severe COPD, and the benefit was sustained for at least $15 \mathrm{~min}$ but had disappeared at $30 \mathrm{~min}$. To our knowledge, this is the first study to use body plethysmography to address the effects of CPAP upon pulmonary volumes and $\mathrm{R}_{\mathrm{aw}}$ in stable COPD patients. Other studies of CPAP in stable COPD have yielded conflicting results; nevertheless, there is some evidence that CPAP prevents gas-exchange deterioration, improves quality of life, and reduces the need for hospitalization in patients with hypercapnia or nocturnal hypoventilation. ${ }^{8,19,20}$ In addition to the favorable findings on CPAP for COPD exacerbation, some studies have found that CPAP either during or between exercise sessions can enhance the benefits of pulmonary rehabilitation. ${ }^{1,2,21,22}$ However, the underlying mechanisms of CPAP benefits are not fully understood. Since the applied PEEP given by CPAP counterbalances auto-PEEP, decreasing the pressure gradient between the mouth and alveoli at end expiration, one theory is that CPAP rests chronically fatigued respiratory muscles. The load reduction on the respiratory muscle pump seems to restore both central chemosensitivity and central drive to breathe. ${ }^{23}$ Additionally, a low level of CPAP can reduce the inspiratory swings in esophageal and transdiaphragmatic pressure and the amount of both paradoxical motion and expiratory recruitment of the abdominal muscles, ${ }^{24}$ by reducing auto-PEEP and the elastic work carried out.

We found that CPAP significantly increased inspiratory capacity and significantly decreased RV, FRC, and TLC. This inspiratory capacity improvement is very similar to that reported by Soares et al, ${ }^{6}$ who observed an average increase of $6.7 \%$ from baseline in responder patients. Soares et al did not measure RV, FRC, and TLC. Our results also agree with those of Díaz et $a{ }^{8}{ }^{8}$ who found that short-term noninvasive ventilation (bi-level positive airway pressure) significantly reduced RV (from $201 \pm 48 \%$ of predicted to $165 \pm 49 \%$ of predicted, $P<.001$ ) and TLC (from $173 \pm 36 \%$ of predicted to $148 \pm 35 \%$ of predicted, $P<.001)$ in stable COPD patients. However, Díaz et al measured lung volumes with the nitrogen-washout method, the accuracy of which depends on all parts of the lung being well ventilated. The plethysmographic TLC value is often higher than that measured with the nitrogen washout, and patients with emphysema can have a $\geq 1$-L TLC difference between the methods. ${ }^{14,24}$ Soares et $\mathrm{al}^{6}$ and Díaz et $\mathrm{al}^{8}$ assessed only the immediate effects of noninvasive ventilation.

A possible explanation for the lung volumes reduction after CPAP is the increase in expiratory time, which could favor the emptying of slow-time-constant lung units. Although Díaz et $\mathrm{al}^{8}$ found that a lower end-expiratory lung volume could be reached at the end of each CPAP session and maintained afterward by a newly adopted spontaneous pattern of breathing, the patients they studied returned to their baseline RV, FRC, and TLC after $30 \mathrm{~min}$.

An acceptable plethysmography panting maneuver requires a certain degree of subject coordination. ${ }^{24}$ In subjects with severe airway obstruction, relatively minor changes in measured FRC can relate to small adjustments of position, anxiety, minute ventilation, and point of shutter closure, and one or more of these factors might have been operative on their second exposure to the plethysmograph.

We selected a CPAP pressure of $8 \mathrm{~cm} \mathrm{H}_{2} \mathrm{O}$ based on previous investigations, and the fact that $\mathrm{CPAP}$ of $8 \mathrm{~cm} \mathrm{H}_{2} \mathrm{O}$ does not increase hyperinflation in COPD patients. ${ }^{12,25,26}$ Increased hyperinflation has been observed at higher CPAP levels. Lim found increased FRC when CPAP increased above $10 \mathrm{~cm} \mathrm{H}_{2} \mathrm{O} .{ }^{27}$ Therefore, CPAP greater than $10 \mathrm{~cm} \mathrm{H}_{2} \mathrm{O}$ may impair the function of the inspiratory muscles if it increases the operating volumes above the levels imposed by expiratory flow limitation, in particular if the operating volumes increase to the point at which the inspiratory muscles work at disadvantageously shorter 
Table 2. Effects of CPAP on Respiratory Rate, $\mathrm{S}_{\mathrm{pO}_{2}}$, Heart Rate, and Blood Pressure

\begin{tabular}{lcccc}
\hline \hline & $\begin{array}{c}\text { Before } \\
\text { CPAP }\end{array}$ & $\begin{array}{c}\text { Immediately } \\
\text { after CPAP }\end{array}$ & $\begin{array}{c}15 \text { min } \\
\text { after CPAP }\end{array}$ & $\begin{array}{c}30 \text { min } \\
\text { after CPAP }\end{array}$ \\
\hline Respiratory rate (breaths/min) & $29 \pm 7$ & $24 \pm 8$ & $24 \pm 7$ & $28 \pm 7$ \\
$\mathrm{~S}_{\mathrm{pO}_{2}}(\%)$ & $92 \pm 2$ & $96 \pm 2$ & $96 \pm 2$ & $93 \pm 2$ \\
Heart rate (beats/min) & $104 \pm 8$ & $103 \pm 8$ & $102 \pm 8$ & $103 \pm 9$ \\
Systolic blood pressure (mm Hg) & $131 \pm 12$ & $131 \pm 12$ & $131 \pm 11$ & $131 \pm 12$ \\
Diastolic blood pressure (mm Hg) & $82 \pm 11$ & $80 \pm 11$ & $80 \pm 10$ & $80 \pm 12$
\end{tabular}

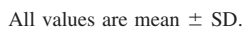

Table 3. Effects of CPAP on Plethysmography Variables*

\begin{tabular}{|c|c|c|c|c|}
\hline & $\begin{array}{l}\text { Before } \\
\text { CPAP }\end{array}$ & $\begin{array}{l}\text { Immediately } \\
\text { after CPAP }\end{array}$ & $\begin{array}{l}15 \mathrm{~min} \\
\text { after CPAP }\end{array}$ & $\begin{array}{c}30 \mathrm{~min} \\
\text { after CPAP }\end{array}$ \\
\hline Inspiratory capacity (L) & $1.4 \pm 0.6$ & $1.6 \pm 0.6$ & $1.7 \pm 0.6$ & $1.4 \pm 0.6$ \\
\hline Inspiratory capacity ( $\%$ predicted) & $72 \pm 22$ & $81 \pm 20$ & $87 \pm 24$ & $72 \pm 22$ \\
\hline $\operatorname{TLC}(\mathrm{L})$ & $7.3 \pm 1.7$ & $5.9 \pm 1.4$ & $5.7 \pm 1.4$ & $7.1 \pm 1.5$ \\
\hline TLC (\% predicted) & $148 \pm 27$ & $120 \pm 16$ & $115 \pm 17$ & $145 \pm 24$ \\
\hline FRC (L) & $5.9 \pm 1.4$ & $4.3 \pm 1.0$ & $4.0 \pm 0.9$ & $5.7 \pm 1.2$ \\
\hline FRC (\% predicted $)$ & $196 \pm 44$ & $145 \pm 25$ & $133 \pm 24$ & $192 \pm 45$ \\
\hline $\mathrm{RV}(\mathrm{L})$ & $5.1 \pm 1.4$ & $3.7 \pm 0.9$ & $3.3 \pm 0.9$ & $4.9 \pm 1.1$ \\
\hline RV (\% predicted) & $257 \pm 66$ & $185 \pm 40$ & $167 \pm 37$ & $250 \pm 66$ \\
\hline RV/TLC (\% predicted) & $69 \pm 8$ & $62 \pm 8$ & $59 \pm 9$ & $69 \pm 8$ \\
\hline $\mathrm{R}_{\mathrm{aw}}\left(\mathrm{cm} \mathrm{H}_{2} \mathrm{O} / \mathrm{L} / \mathrm{s}\right)$ & $7.3 \pm 2.5$ & $4.9 \pm 1.7$ & $4.4 \pm 1.6$ & $6.6 \pm 2.0$ \\
\hline
\end{tabular}

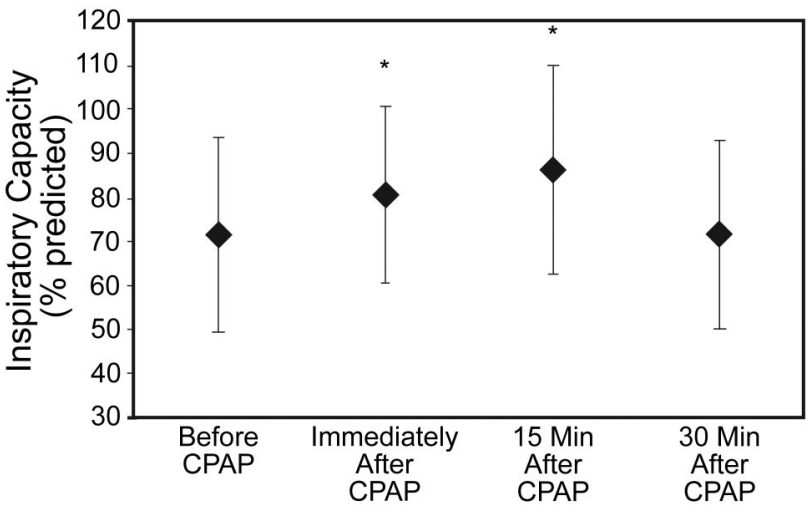

Fig. 2. Inspiratory capacity before and after CPAP. * Significantly different from baseline (before CPAP).

lengths or less favorable mechanical advantage. ${ }^{9}$ Moreover, hemodynamic consequences can be expected as a direct result of both dynamic hyperinflation and auto-PEEP. The increase in lung volume may reduce venous return, directly through compression of the vena cava and right heart, and indirectly through an increase in right atrial

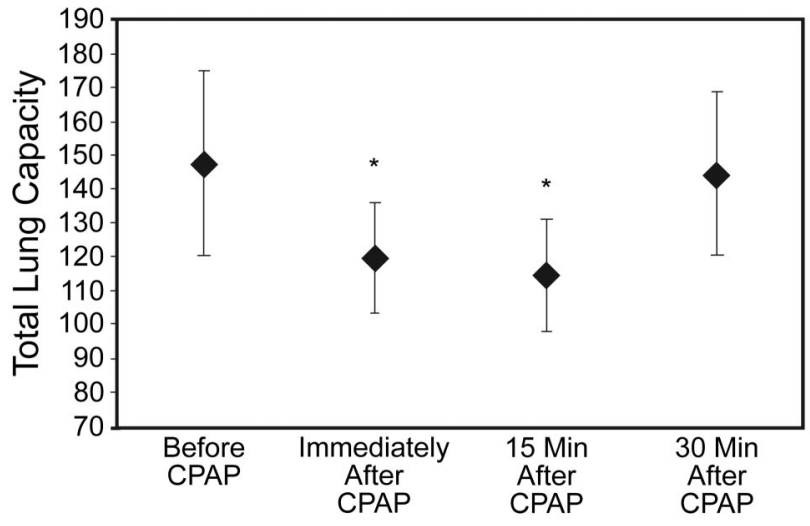

Fig. 3. Total lung capacity before and after CPAP. * Significantly different from baseline (before CPAP).

pressure, decreasing the pressure gradient for venous return. ${ }^{10,14}$

The effects of nasal CPAP on the lung parenchyma of stable COPD patients has been assessed via high-resolution computed tomography. In a recently published study, Holanda et $\mathrm{al}^{28}$ obtained high-resolution computed tomog- 


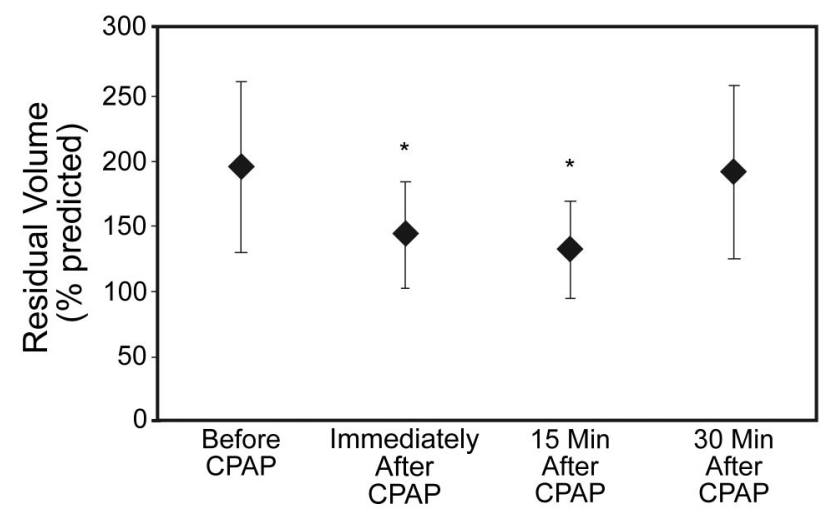

Fig. 4. Residual volume before and after CPAP. * Significantly different from baseline (before CPAP).

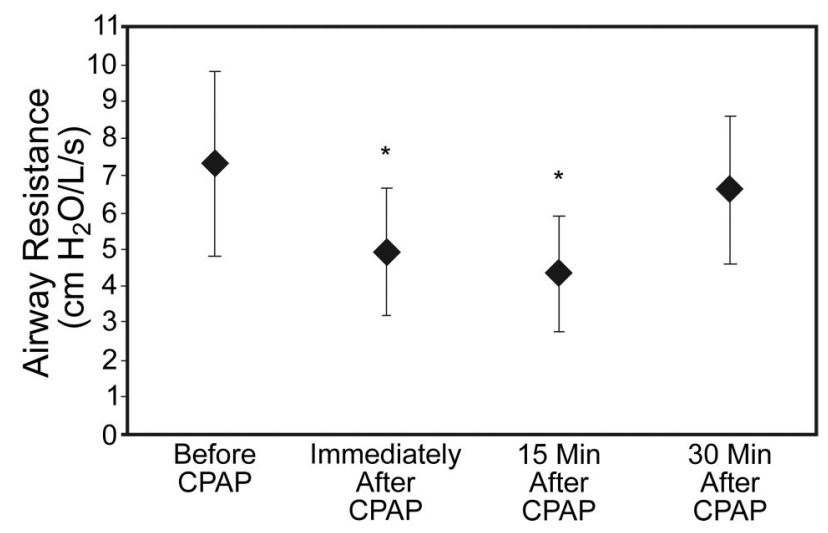

Fig. 5. Airway resistance before and after CPAP. * Significantly different from baseline (before CPAP).

raphy of 11 stable spontaneously breathing COPD patients immediately after CPAP trials of 5,10 , and $15 \mathrm{~cm} \mathrm{H}_{2} \mathrm{O}$. $\mathrm{CPAP}$ at $5 \mathrm{~cm} \mathrm{H}_{2} \mathrm{O}$ caused regional lung deflation, whereas CPAP at 10 and $15 \mathrm{~cm} \mathrm{H}_{2} \mathrm{O}$ increased the emphysematous zones in all of the pulmonary regions. Those results are consistent with those observed in relation to lung function.

Measurement of $\mathrm{R}_{\mathrm{aw}}$ may help distinguish airway obstruction due to intrinsic narrowing of the airway by mucus hypersecretion and bronchial wall inflammation (eg, chronic bronchitis) or to the loss of lung elastic recoil (eg, emphysema). Although $\mathrm{R}_{\mathrm{aw}}$ is elevated in both disorders, the increase is usually more marked in chronic bronchitis. ${ }^{24,29}$ In the Van Noord et al study, ${ }^{29}$ the resistance values were only marginally higher than in normal subjects. One explanation could be the predominance of subjects with emphysema rather than with chronic bronchitis.

After CPAP at $8 \mathrm{~cm} \mathrm{H}_{2} \mathrm{O}$ the results showed significant $\mathrm{R}_{\mathrm{aw}}$ reduction. O'Donoghue et al ${ }^{30}$ used CPAP increments of $1 \mathrm{~cm} \mathrm{H}_{2} \mathrm{O}$ in patients with severe stable COPD and found an $\mathrm{R}_{\mathrm{aw}}$ reduction tendency, from $16.5 \mathrm{~cm} \mathrm{H}_{2} \mathrm{O} / \mathrm{L} / \mathrm{s}$ with 0 CPAP to $3.5 \mathrm{~cm} \mathrm{H}_{2} \mathrm{O} / \mathrm{L} / \mathrm{s}$ at CPAP of $10 \mathrm{~cm} \mathrm{H}_{2} \mathrm{O}$.
That difference was not significant $(P=.08)$. Smith and Marini ${ }^{10}$ reported that applied PEEP may reduce $\mathrm{R}_{\mathrm{aw}}$ and the mechanical work of breathing in patients with severe COPD. The suggested mechanisms to explain the reduced $\mathrm{R}_{\mathrm{aw}}$ are the decrease of airway wall edema, the stretching open of chronically fibrosed airways, and the recruitment of normal lung, previously collapsed by hyperinflated emphysematous areas, with a consequent increase in airway tethering. ${ }^{21,31}$

Like previous authors, we did not measure auto-PEEP. Since all the patients had severe air-flow obstruction, we assumed that the results were related to the impact of applied PEEP on expiratory flow limitation and auto-PEEP. Our findings support the adjustment of PEEP in the therapeutic setting, especially when the foremost objective is to improve respiratory mechanics and reduce the respiratory muscle overload.

It could be conjectured that there is a relationship between the duration of CPAP and the duration of its benefits, or that a higher CPAP pressure might produce greater effects or longer duration, but further studies are necessary to answer those questions.

\section{Conclusions}

CPAP reduces lung volumes and $\mathrm{R}_{\mathrm{aw}}$ in patients with severe stable COPD, and the benefits last for 15-30 min after CPAP.

\section{REFERENCES}

1. Duiverman ML, Wempe JB, Bladder G, Jansen DF, Kerstjens HAM, Zijlstra JG, et al. Nocturnal non-invasive ventilation in addition to rehabilitation in hypercapnic patients with COPD. Thorax 2008; 63(12):1052-1057.

2. Bianchi L, Foglio K, Pagani M, Vitacca M, Rossi A, Ambrosino N. Effects of proportional assist ventilation on exercise tolerance in COPD patients with chronic hypercapnia. Eur Respir J 1998;11(2): 422-427.

3. O'Donnell DE, Revill SM, Webb KA. Dynamic hyperinflation and exercise intolerance in chronic obstructive pulmonary disease. Am J Respir Crit Care Med 2001;164(5):770-777.

4. Marin JM, Carrizo SJ, Gascon M, Sanchez A, Gallego B, Celli BR. Inspiratory capacity, dynamic hyperinflation, breathlessness, and exercise performance during the 6-minute-walk test in chronic obstructive pulmonary disease. Am J Respir Crit Care Med 2001;163(6): 1395-1399.

5. Pepe PE, Marini JJ. Occult positive end-expiratory pressure in mechanically ventilated patients with airflow obstruction: the auto-PEEP effect. Am Rev Respir Dis 1982;126(1):166-170.

6. Soares SMTP, Oliveira RARA, Franca SA, Rezende SM, Dragosavac D, Kacmarek RM, et al. Continuous positive airway pressure increases inspiratory capacity of COPD patients. Respirology 2008; 13(3):387-393.

7. Tobin MJ, Lodato RF. PEEP, auto-PEEP, and waterfalls. Chest 1989; 96(3):449-451.

8. Díaz O, Bégin P, Torrealba B, Jover E, Lisboa C. Effects of noninvasive ventilation on lung hyperinflation in stable hypercapnic COPD. Eur Respir J 2002;20(6):1490-1498. 


\section{CPAP Decreases Lung Hyperinflation in Patients With Stable COPD}

9. Simkovitz P, Brown K, Goldberg P, Milic-Emili J, Gottfried S. Interaction between intrinsic and externally applied PEEP during mechanical ventilation. Am Rev Respir Dis 1987;135(1):202.

10. Smith TC, Marini JJ. Impact of PEEP on lung mechanics and work of breathing in severe airflow obstruction. J Appl Physiol 1988; 65(4): 1488-1499.

11. Kondili E, Alexopoulou C, Prinianakis G, Xirouchaki N, Georgopoulos D. Pattern of lung emptying and expiratory resistance in mechanically ventilated patients with chronic obstructive pulmonary disease. Intensive Care Med 2004;30(7):1311-1318.

12. Kaczka DW, Ingenito EP, Body SC, Duffy SE, Mentzer SJ, DeCamp $\mathrm{MM}$, et al. Inspiratory lung impedance in COPD: effects of PEEP and immediate impact of lung volume reduction surgery. J Appl Physiol 2001;90(5):1833-1841.

13. Dellacà RL, Rotger $\mathrm{M}$, Aliverti $\mathrm{A}$, Navajas $\mathrm{D}$, Pedotti $\mathrm{A}$, Farré R. Noninvasive detection of expiratory flow limitation in COPD patients during nasal CPAP. Eur Respir J 2006;27(5):983-991.

14. Ranieri VM, Dambrosio M, Brienza N. Intrinsic PEEP and cardiopulmonary interaction in patients with COPD and acute ventilatory failure. Eur Respir J 1996;9(6):1283-1292.

15. Rabe KF, Hurd S, Anzueto A, Barnes PJ, Buist SA, Calverley P, et al. Global strategy for the diagnosis, management, and prevention of chronic obstructive pulmonary disease: GOLD executive summary. Am J Respir Crit Care Med 2007;176(6):532-555.

16. American Thoracic Society. Standardization of spirometry: 1994 update. Am J Respir Crit Care Med 1995;152(3):1107-1136.

17. Knudson RJ, Lebowitz MD, Holberg CJ, Burrows B. Changes in the normal maximal expiratory flow-volume curve with growth and aging. Am Rev Respir Dis 1983;127(6):725-734.

18. Goldman HI, Becklake MR. Respiratory function tests; normal values at mean: altitudes and the prediction of normal results. Am Rev Tuberc 1959;79(4):457-467.

19. Carlucci A, Delmastro M, Rubini F, Fracchia C, Nava S. Changes in the practice of non-invasive ventilation in treating COPD patients over 8 years. Intensive Care Med 2003;29(3):419-425.
20. Mehta S, Hill NS. Noninvasive ventilation. Am J Respir Crit Care Med 2001;163(2):540-577.

21. Ambrosino N. Exercise and noninvasive ventilatory support. Monaldi Arch Chest Dis 2000;55(1):242-246.

22. Garrod R, Mikelsons C, Paul EA, Wedzicha JA. Randomized, controlled trial of domiciliary noninvasive positive pressure ventilation and physical training in severe COPD. Am J Respir Crit Care Med 2000;162(4):1335-1341.

23. Elliott MW. Domiciliary non-invasive ventilation in stable COPD? Thorax 2009;64(7):553-556.

24. Ruppel GL. Lung volumes and gas distribution tests. In: Ruppel GL, editor. Manual of pulmonary function testing. St. Louis: Mosby; 1998:69-94.

25. Navalesi P, Maggiore SM. Positive end-expiratory pressure. In: Tobin MJ, editor. Principles and practice of mechanical ventilation. New York: McGraw-Hill; 2006:273-325.

26. Goldberg P, Reissmann H, Maltais F, Ranieri M, Gottfried SB. Efficacy of noninvasive CPAP in COPD with acute respiratory failure. Eur Respir J 1995;8(11):1894-1900.

27. Lim TK. Effect of nasal-CPAP on patients with chronic obstructive pulmonary disease. Singapore Med J 1990;31(3):223-227.

28. Holanda MA, Fortaleza SCB, Alves-de-Almeida M, Winkeler GFP, Reis RC, Felix JH, et al. Continuous positive airway pressure effects on regional lung aeration in COPD patients: a high-resolution CT study. Chest 2010;138(2):305-314.

29. Van Noord JA, Clément J, Van de Woestijne KP, Demedts M. Total respiratory resistance and reactance in patients with asthma, chronic bronchitis, and emphysema. Am Rev Respir Dis 1991;143(5):922927.

30. O'Donoghue FJ, Catcheside PG, Jordan AS, Bersten AD, McEvoy RD. Effect of CPAP on intrinsic PEEP, inspiratory effort, and lung volume in severe stable COPD. Thorax 2002;57(6):533-539.

31. Burns GP, Gibson GJ. A novel hypothesis to explain the bronchconstrictor effect of deep inspiration in asthma. Thorax 2002;57(2):116 119 